\title{
MUDANÇAS RECENTES NA ESTRUTURA DE EMPREGO EM PORTUGAL SEGMENTAÇÃO E POLARIZAÇÃO
}

\author{
RECENT CHANGES IN THE EMPLOYMENT STRUCTURE IN \\ PORTUGAL \\ SEGMENTATION AND POLARIZATION
}

\author{
João Dias \\ Instituto Superior de Economia e Gestão (ISEG) \& Unidade de Estudos sobre Complexidade e Economia (UECE), \\ Universidade de Lisboa. Rua Miguel Lupi 20,1249-078 Lisboa, Portugal. Email: jdias@iseg.ulisboa.pt
}

\section{Ilona Kovács}

Centro de Investigação em Sociologia Económica e das Organizações, Instituto Superior de Economia e Gestão (SOCIUS-ISEG), Universidade de Lisboa. Rua Miguel Lupi 20, 1249-078 Lisboa, Portugal. Email: ilona@iseg.ulisboa.pt

\author{
Maria da Conceição Cerdeira \\ Centro de Investigação em Sociologia Económica e das Organizações, Instituto Superior de Economia e Gestão \\ (SOCIUS-ISEG), Universidade de Lisboa. Rua Miguel Lupi 20, 1249-078 Lisboa, Portugal. Email: mcscerdeira@gmail.com
}

\begin{abstract}
Resumo: Neste artigo analisamos a segmentação do mercado de trabalho português, as tendências de mudança da estrutura do emprego e a sua diferenciação por idade, género, escolaridade e tipo de contrato de 2010 a 2015, subdivido em dois períodos: 2010-13 (período mais recessivo da crise) e 2013-15 (período do início da retoma económica). O texto apoia-se nas teorias da segmentação e da polarização do emprego e, metodologicamente, nos estudos da Eurofound, utilizando microdados dos Quadros de Pessoal.

Concluímos que à segmentação, uma característica marcante do mundo laboral português de longa data, se associou um padrão de polarização negativa (2010-13) e de deterioração (downgrading) da estrutura do emprego (2013-15). Assim, na fase da crise, a maior redução ocorreu nos empregos de níveis salariais intermédios. Na fase de retoma, foram os empregos com remuneração mais baixa e baseadas em contratos não permanentes que registaram maior incremento.
\end{abstract}

Palavras-chave: emprego, polarização, segmentação, Portugal.

\begin{abstract}
In this article we analyze the segmentation of the Portuguese labor market, the trends of change in the structure of employment and its differentiation by age, gender, schooling and type of contract from 2010 to 2015, subdivided into two periods: 2010-13 (the most recessionary period of the crisis) and 2013-15 (the beginning of the economic recovery). The paper is based on the theories of segmentation and polarization of employment and, methodologically, on Eurofound studies, using microdata from Quadros de Pessoal.

We conclude that segmentation, a long-standing feature of the Portuguese labor market, was associated with a negative polarization pattern (2010-13) and downgrading of the employment structure (2013-15). Thus, during the crisis, the highest reduction occurred in intermediate wage levels jobs. In the recovery phase, lowest-paid jobs, based on non-permanent contracts, recorded the largest increase.
\end{abstract}

Keywords: employment, polarization, segmentation, Portugal. 


\section{Introdução}

A quebra da homogeneidade do emprego fordista é uma das tendências mais marcantes das economias desenvolvidas, nas últimas décadas. Uma das manifestações desta quebra é o crescimento de formas flexíveis frequentemente precárias do emprego (trabalho temporário, trabalho com contratos de curta duração, trabalho a tempo parcial, falso trabalho independente, etc.), com forte concentração em determinados segmentos de emprego (jovens, mulheres, imigrantes). À segmentação do mercado de trabalho, tema relativamente bem estudado e sempre atual, associa-se um fenómeno progressivo, mais recentemente percebido, que é a polarização da estrutura do emprego, expresso na redução do peso dos níveis intermédios da grelha de qualificações e de salários.

A polarização do emprego suscitou já um acervo bastante importante de estudos no âmbito da economia do trabalho nos Estados Unidos e na Europa, na última década. Todavia, as causas, a escala, a natureza e a durabilidade deste processo não são consensuais. Acresce que poucos destes estudos exploram as dinâmicas da mudança ocupacional e a sua diferenciação em torno de características socioeconómicas dos trabalhadores tais como a idade, o género, o nível de habilitação escolar ou o tipo de contrato (Tüzemen \& Willis, 2013; Yoon \& Chung, 2015). Por sua vez, os estudos sociológicos que exploraram a segmentação do mercado de trabalho, nomeadamente a incidência das formas flexíveis e precárias de emprego levando em conta o género (Casaca, 2005, 2012; Maruani, 2003; Rubery, 2007; Rubery \& Piasna, 2017) e a idade (Alves, Cantante, Baptista \& Carmo, 2011; Golsch, 2003; Kovács, 2014; Kovács \& Chagas Lopes, 2012; López Calle \& Castillo, 2004; Marques, 2010), não tendem a estabelecer ligação com as tendências de mudança da estrutura ocupacional.

Apoiando-se nos contributos da economia do trabalho e da sociologia do trabalho e do emprego que se consideram complementares, este artigo pretende contribuir para um melhor entendimento das mudanças recentes no emprego, com ênfase na segmentação e na polarização. A redução da segmentação do mercado de trabalho foi uma das prioridades inscritas no Memorando de Entendimento acordado pelo Governo Português com a Troika (Fundo Monetário Internacional (FMI), Banco Central Europeu (BCE) e Comissão Europeia (CE)), que conduziu a alterações muito profundas da legislação laboral. Um primeiro objetivo do artigo é avaliar o impacto desta reforma, através da análise das tendências recentes da segmentação do mercado de trabalho. Um segundo objetivo pretende identificar o padrão de evolução da qualidade do emprego, as diferenças entre os ciclos mais agudo da crise e o início da retoma económica, utilizando a diferenciação segundo 
a idade, o género, o nível de escolaridade e o tipo de contrato. A sua pertinência prende-se com o fato de Portugal ter sido um dos países mais afetados pela crise (a taxa de desemprego aproximou-se de $17 \%$ no $1^{\circ}$ trimestre de 2013 , a terceira maior taxa na EU, a seguir à Grécia e Espanha) e ter implementado um conjunto de reformas profundas do mercado de trabalho enquadradas pelo Memorando de Entendimento atrás referido.

Cronologicamente analisa-se o período de 2010-2015, dividido em dois subperíodos: 2010-2013 e 2013-2015. A demarcação do período 2010-15, justifica-se, no que se refere ao seu início (2010), por se tratar do ano imediatamente anterior à fase mais aguda da crise no caso português, para além de evitar a descontinuidade de dados estatísticos com a adoção nesse ano da nova Classificação Portuguesa das Profissões. O último ano do período (2015) resulta de constrangimentos no acesso a microdados mais recentes no momento em que o texto foi elaborado. A divisão dos subperíodos deve-se ao facto de considerarmos 2013 como o ano-charneira de uma fase mais aguda da crise e do início da retoma económica.

O texto compreende para além desta introdução (ponto 1) mais quatro pontos. O ponto 2 é dedicado à revisão das teorias da segmentação do mercado de trabalho e da polarização do emprego. No ponto 3 referem-se alguns fatores suscetíveis de explicar o forte enraizamento da segmentação do mercado de trabalho português e apresentam-se dados sobre a sua evolução recente. O ponto 4 é dedicado aos aspetos metodológicos que apoiaram o estudo empírico dos padrões de mudança da estrutura do emprego e cujos resultados são apresentados no ponto 5. Por último, no ponto 6, apresentam-se algumas notas conclusivas.

\section{Revisão teórica}

A divisão ou segmentação do mercado de trabalho tem sido um tema importante de investigação e debate, desde os anos 70. Numa primeira fase, a tónica da literatura foi essencialmente colocada na dualização, ou seja, no aumento das desigualdades em termos de salários e de condições de trabalho entre os dois segmentos do mercado de trabalho: o primário (ou mercado de trabalho interno) e o secundário (ou mercado de trabalho externo). Enquanto o primeiro inclui empregos estáveis, bem pagos, com perspetivas de carreira e boas condições de trabalho, o segundo compreende empregos inseguros, mal pagos, sem perspetivas de carreira e más condições de trabalho, sendo a mobilidade entre os dois sectores reduzida. A dualização foi considerada uma tendência comum aos países industrialmente mais avançados (Berger \& Piore, 1980; Doeringer \& Piore, 1971; Piore, 1972, 1978). 
Desde finais da década de 1980, com as grandes mudanças do contexto socioeconómico, de que se destaca a intensificação da concorrência ao nível global, a financeirização da economia e a difusão das tecnologias de informação e comunicação, bem como a expansão de formas flexíveis de emprego, a abordagem dualista passou a considerar outras divisões: empregos standard versus empregos atípicos (Kalleberg, 2000, 2011; Rosenberg, 1989, 2007; Rosenberg \& Lapidus, 1999), insiders (com emprego protegido e negociação salarial) versus outsiders (desempregados e trabalhadores com emprego não protegido) (Edwards, 1979; Lindbeck \& Snower, 2001; Paugam, 2000), trabalhadores do núcleo duro das empresas (centrais) versus trabalhadores periféricos (Atkinson, 1985; Castells, 1998; Harrison, 1994).

Paralelamente, na área da sociologia do trabalho e do emprego, surgiu uma nova abordagem com ênfase na análise da diferenciação de múltiplos segmentos de emprego, portadores de diferentes graus de desigualdades e vulnerabilidades. Nesta perspetiva, a disseminação de práticas de flexibilização no mundo do trabalho, resulta não apenas numa simples divisão dualista entre trabalhadores com empregos standard e trabalhadores com empregos flexíveis, mas numa crescente diferenciação das situações de emprego e dos trabalhadores. Quer dizer que trabalhadores da mesma empresa com as mesmas qualificações e competências mesmo dentro da mesma empresa podem ser detentores de contratos, salários e condições de trabalho bem diferentes. Nesta abordagem, entre os fatores de segmentação, são considerados a estrutura económica, as políticas dos empregadores, as estratégias sindicais e as políticas públicas (Barbieri, 2009; Brewster, Mayne \& Tregaskis, 1997; Gallie, White, Cheng \& Tomlinson, 1998; Kalleberg, 2000, 2011; Kovács, 2005; Paugam, 2000; Rosenberg, 1989, 2007). A análise da precariedade do emprego ganhou particular relevância. A precariedade do emprego não se reduz ao tipo de vínculo contratual, embora este seja uma dimensão importante. Há um conjunto de outras dimensões, tais como, baixos salários e benefícios sociais, trabalho pouco interessante, mal pago e pouco reconhecido, incerteza quanto à continuidade do emprego, falta de oportunidades de aprendizagem/formação e de perspetivas de evolução profissional, falta ou insuficiente proteção legal e institucional, forte vulnerabilidade económica e restrição dos direitos sociais (baseados no emprego estável) (Castells, 1998; Kalleberg, 2011; Kovács, 2005; Kovács \& Casaca, 2007; Paugam, 2000; Rueda, 2014).

Nos últimos anos, no âmbito da economia do trabalho, ganhou particular relevância, a investigação sobre a polarização do emprego, interligada com o debate sobre a compreensão e explicação das crescentes desigualdades salariais e sociais nos países desenvolvidos (Acemoglu, 2002; Acemoglou \& Autor, 2011; Autor, 2010, 2013; Autor \& Dorn, 2013; Autor, Katz \& Kearney, 2006; Autor, Levy \& Murnane, 2003; Autor, Katz \& Krueger, 1998; Goldin \& Katz, 1996; Goos \& Manning, 2007). A 
polarização designa a tendência para o acréscimo relativo dos empregos no topo e na base da hierarquia ocupacional/salarial, em detrimento dos empregos de níveis médios. Esta tendência é explicada pelo impacto diferenciado das tecnologias de informação e comunicação nos diversos tipos de tarefas (Autor, Levy \& Murnane, 2003; Goos, Manning \& Salomons, 2011). As tarefas rotineiras fortemente concentradas nas ocupações de qualificação/salário de nível médio são suscetíveis à automação, razão pela qual diminui o emprego nesse nível. Já as tarefas não rotineiras não são substituíveis pela automação. As tarefas não rotineiras altamente qualificadas, requerendo competências de resolução de problemas, criatividade, intuição, persuasão, capacidade analítica e de comunicação que caracterizam as ocupações profissionais, técnicas e de gestão, são realizadas por trabalhadores com alto nível de educação, cujo trabalho é positivamente afetado pela evolução tecnológica que complementa as suas capacidades. Por sua vez, as tarefas manuais não rotineiras de baixa qualificação que requerem competências interpessoais, são pouco afetadas pela mudança tecnológica. A procura por este tipo de trabalhadores tende a aumentar em comparação com os do nível médio, levando ao aumento da proporção dos empregos situados na base da hierarquia ocupacional. Foi essa perspetiva, cujo modelo formal foi apresentado por Autor, Levy \& Murnane (2003), que se tornou a mais influente fundamentando os estudos que identificaram a polarização do emprego no Reino Unido (Goos \& Manning, 2007) e nos EUA (Acemoglu \& Autor, 2011; Autor, Katz \& Kearney, 2006). A tendência para a polarização, identificada nos Estados Unidos e no Reino Unido a partir dos anos 80, parece ter-se estendido a outros países industrializados a partir dos anos 90. Assim, alguns autores indicam a generalização dessa tendência nas economias avançadas (Goos, Manning \& Salomons, 2009; Goos, Salomons \& Vandeweyer, 2013). Porém, o tema da polarização está longe de ser consensual, divergindo os autores, com base em estudos empíricos, tanto sobre as suas causas como sobre a sua natureza e dimensão.

Particularmente relevante é a abordagem que põe a ênfase nas políticas públicas e instituições sociais como fatores modeladores do impacto da evolução tecnológica no emprego. Estudos que seguem esta abordagem têm vindo a identificar diversos padrões de mudança da estrutura do emprego: para além da polarização, upgrading (melhoria), ou seja, o crescimento relativamente mais elevado do emprego nos níveis médio e superior da hierarquia ocupacional e downgrading (degradação) referente ao crescimento relativamente elevado na base. Os resultados desses estudos mostram que os diferentes padrões de mudança da estrutura de emprego identificados estão associados a diferentes modelos institucionais e de regulação do emprego (Fernández-Macías, 2012; Oesch \& Menès, 2011). Nesta ótica, a desregulação do mercado trabalho afeta a estrutura do emprego, pelo estímulo ao crescimento do emprego com 
baixos salários, facilitando ou intensificando a tendência para a polarização. Pelo contrário, a tendência para a polarização pode ser neutralizada através da dissuasão da expansão dos empregos mal pagos por via do salário mínimo elevado e/ ou da legislação protetora do emprego, bem como pela criação de empregos no serviço público (Eurofound, 2013, 2014, 2015, 2016, 2017; Fernández-Macías, 2012; Oesch, 2013; Oesch \& Menès, 2011; Rubery \& Piasna, 2017).

Estudos recentes mostram que os padrões de evolução do emprego são sensíveis aos ciclos económicos. A polarização pode acelerar-se em períodos recessivos, como aquele que vivemos com o desencadear da crise financeira de 2008, devido à maior volatilidade dos sectores da indústria transformadora e da construção civil, caracterizados por concentrarem segmentos muito importantes do emprego em ocupações de nível médio (Eurofound, 2013, 2014, 2015, 2016, 2017; Foote \& Ryan, 2012; Mishel, Schmitt \& Shierholz, 2013; Wright \& Dwyer, 2003).

Relativamente aos Estados Unidos, Autor (2015) e Autor, Dorn e Hanson (2016) assinalam a mudança do padrão da estrutura ocupacional de um padrão polarizado da década de 1990 para um padrão de desqualificação na década de 2000. Esta mudança manifesta-se no relativamente forte crescimento do emprego na base da hierarquia ocupacional e, na desaceleração simultânea do crescimento do emprego nas ocupações intensivas em tarefas abstratas (inferior ao potencial de oferta de trabalhadores altamente qualificados) e uma relativa estagnação do emprego de nível médio. Os autores explicam essa mudança de padrão com fatores económicos, argumentando que a bolha "dot-com" em 2000, o colapso do mercado imobiliário e a crise financeira de 2007-2008, reduziram o investimento em tecnologias de informação e a atividade inovadora em geral que podia aumentar a procura por trabalhadores altamente qualificados. Por sua vez, com entrada da China na Organização Mundial do Comércio, a deslocação de empregos para a China, bem como o aumento acentuado das importações desse mesmo país contribuíram para a redução do emprego nos EUA (Autor, Dorn \& Hanson, 2016).

No que se refere à União Europeia, também foram identificadas mudanças no padrão da evolução da estrutura do emprego: de uma tendência de melhoria de 1998-2007 para uma tendência de polarização no período da crise de 2008-2010 e de 2011-2013, passando para uma tendência de melhoria no subperíodo da retoma do crescimento do emprego de 2013-2016 (Eurofound, 2017).

\section{A segmentação e a polarização no caso português}

A forte segmentação do mercado de trabalho é considerada como um dos problemas centrais do mercado de trabalho português. É um fenómeno fortemente 
enraizado, de longa data, que é transversal à generalidade das atividades económicas (CLBRL, 2007; Dornelas, Ministro, Lopes, Cerdeira, Galego \& Sousa, 2006; ILO, 2013, 2016; OECD, 2010, 2014, 2016, 2017; OIT, 2018). Um dos traços mais importantes desta segmentação é a diferenciação entre insiders e outsiders, baseada na coexistência de vários tipos de contrato, nomeadamente contratos permanentes (por tempo indeterminado) e temporários (a termo certo e incerto, em regime de tarefa e ocasional) ${ }^{1}$, com regimes de segurança no emprego e no desemprego muito diferenciados (Centeno \& Novo, 2012; Cerdeira, Casaca, Santos, Sampaio \& Silva, 1999; CLBRL, 2007; Kovács, 2014; Kovács, Moniz, Cerdeira \& Bairrada, 1994; OECD, 2010, 2014, 2017, 2018; OIT, 2018). Em comparação com os permanentes, os temporários enfrentam riscos desproporcionados de mobilidade entre empregos, de desemprego e são mais propensos a ocupar postos de trabalho "periféricos" ou secundários com piores condições de trabalho e menores oportunidades de evoluir na carreira profissional. Como é sublinhado pela CLBRL (2007), os contratos a termo acumulam desvantagens salariais que são constantes ao longo do ciclo de vida e que se agravam na fase final da vida profissional. O dualismo do mercado de trabalho, baseado na diferenciação entre insiders e outsiders, vai a par com o dualismo do sistema de welfare (Dornelas, Ministro, Lopes, Albuquerque, Paixão \& Santos, 2011; Valadas, 2017).

O sistema dual contribui para que Portugal se tenha vindo a posicionar entre as economias europeias com um dos graus mais elevados de desigualdade e com uma proporção mais elevada de empregos comummente designados de "atípicos" (Centeno \& Novo, 2012).

A dualização do mercado trabalho é consequência de um conjunto amplo de fatores. Entre estes, importa referir as insuficiências da negociação coletiva no que se refere ao papel que poderia desempenhar na promoção da flexibilidade interna das empresas (polivalência e adaptabilidade do tempo de trabalho) e no melhor ajustamento dos recursos humanos às exigências de adaptação das empresas à mudança do contexto económico (Cerdeira, 2004); as fracas políticas ativas de emprego, com expressão no baixo nível de afetação de recursos nacionais quando comparado com a média dos países comunitários (Dornelas, Ministro, Lopes, Albuquerque, Paixão \& Santos, 2011); a insuficiência de ações inspetivas pelas instituições que tutelam o trabalho e o elevado peso de pequenas e médias empresas na composição do tecido empresarial português. Estes fatores conjugam-se com as reformas parciais da legislação do trabalho feitas ao longo dos anos, que se caracterizam por promover a flexibilidade externa das empresas através da criação de "incentivos" à contratação não permanente, ao mesmo tempo que deixavam imutável a segurança dos contratos permanentes. Assim, os contratos a termo que começaram por funcionar como uma base de experimentação, ou seja, como uma espécie de "pré-recrutamento" de 
trabalhadores efetivos, tornaram-se numa forma de ajustamento dos recursos humanos nas empresas (Kovács, 2005).

A liberalização dos contratos a prazo tem uma longa história que não cabe aqui desenvolver². O seu início data de 1976 (Decreto-Lei 781/1976), mas a sua grande difusão tem como marcos históricos a publicação do Decreto-Lei 64-A/89 e o Código de Trabalho de 2003 (Lei 99/2003). Concretamente, o último, veio a permitir que os contratos a termo até então com uma duração máxima de 36 meses, no limite de duas renovações, passassem a ter uma renovação por três vezes e até a um limite de seis anos. Além disso, foram introduzidos critérios cumulativos dificultando a identificação de situações de assalariamento. O Código de 2009 (Lei $7 / 2009)^{3}$, que seguiu uma política diferente em matéria de flexibilidade, voltou a estabelecer limites de três anos, regra também alargada aos contratos com agências de trabalho temporário e contratos de prestação de serviços celebrados com a mesma finalidade entre o trabalhador e a mesma empresa ou grupo de empresas; a relação contratual de assalariamento passou apenas a requerer um único critério; as regras processuais referentes ao despedimento individual foram simplificadas. Com esta reforma, o rigor da LPE (legislação protetora do emprego, medida numa escala de 1 a 5), dos contratos permanentes, cuja avaliação a OECD posicionava entre as mais elevadas dos países que dela fazem parte, sofreu uma ligeira descida (de 4,42 para 4,13), mas ficando longe de corresponder à pressão das instituições internacionais (OECD, FMI e CE) de aproximação dos dois regimes de emprego (temporário e permanente).

Como evidencia a tabela 1, o declínio do indicador da LPE dos contratos permanentes, numa tendência de aproximação à média dos países da $\mathrm{OECD}$, só veio a ocorrer com a reforma legislativa impulsionada pela austeridade nos anos de 2011, 2012 (Lei 23/2012) ${ }^{4}$ e 2013. Esta reforma, considerada pela Troika de alta prioridade e cuja implementação monitorizou, abarcou vertentes muito diversificadas das instituições e das políticas do mercado de trabalho, incluindo: suspensão do contrato de trabalho por motivos económicos; agilização do despedimento individual5; descentralização da negociação coletiva do setor para a empresa; condicionamento à emissão de portarias de extensão; incentivo à utilização de horários de trabalho flexíveis; redução dos montantes devidos pelo trabalho extraordinário; redução dos benefícios de desemprego e do valor da indemnização a pagar pela entidade patronal nas situações de despedimento ${ }^{6}$.

Contudo, se teoricamente as reformas impulsionadas pela Troika deveriam ter promovido a redução da segmentação do mercado de trabalho, já que foi um seus dos objetivos orientadores, os dados da tabela 2 não indicam qualquer evolução nesse sentido. 
Tabela 1 Grau de rigidez da legislação protetora do emprego (LPE): Portugal e média não ponderada dos 34 países membros da OECD em 2013 (1990-2013)

\begin{tabular}{llllllllll}
\hline Tipo de contrato & & $\mathbf{1 9 9 0}$ & $\mathbf{2 0 0 4}$ & $\mathbf{2 0 0 8}$ & $\mathbf{2 0 0 9}$ & $\mathbf{2 0 1 0}$ & $\mathbf{2 0 1 1}$ & $\mathbf{2 0 1 2}$ & $\mathbf{2 0 1 3}$ \\
\hline Contrato & Portugal & \multirow{2}{*}{4,83} & 4,42 & 4,42 & 4,42 & 4,13 & 4,13 & 3,56 & 3,18 \\
permanente & OECD & & & 2,17 & 2,16 & 2,15 & 2,12 & 2,08 & 2,04 \\
\hline Contrato não & Portugal & \multirow{2}{*}{3,38} & 2,56 & 1,94 & 1,94 & 1,94 & 1,94 & 1,94 & 1,81 \\
permanente & OECD & & & 1,75 & 1,75 & 1,76 & 1,74 & 1,74 & 1,72 \\
\hline
\end{tabular}

Fonte: Base de dados da Proteção ao Emprego da OECD, Versão 1 (1985-2013), https://stats.oecd.org/Index.aspx?DataSetCode=EPL_T

A percentagem de trabalhadores temporários em 2017 (22,0\%) é não apenas praticamente a mesma de 10 anos antes $(22,3 \%)$, como não se reduziu a sua desproporcionalidade no confronto com a média da UE28. A diferença é cerca de oito pontos percentuais para todos os grupos sociais, com exceção dos mais jovens (15-24 anos). Este grupo, sendo o mais penalizado por contratos a prazo tanto em Portugal como na UE28, regista no nosso país um acréscimo muito maior: 12,8 pontos percentuais contra 3 pontos percentuais na UE28. Assim, se os mais jovens são em toda a UE28 os mais afetados por contratos temporários, o seu grau de afetação é muito maior no mundo laboral português. Portugal distingue-se ainda da UE28 no que diz respeito à detenção de contratos a prazo involuntários. A diferença supera os 30 pontos percentuais, com ligeiro agravamento em 2017, relativamente a 2007.

A segmentação do mercado de trabalho tem também expressão na importante fatia de trabalhadores que ao longo dos anos foi tipificado como a categoria dos trabalhadores independentes sem assalariados e que os dados do Eurostat situam em 14\% em 2007 e 9\% em 2017 para o grupo etário dos 15-64 anos. Se nestes valores podem ser encontrados trabalhadores que deliberadamente optam por serem independentes, a sua maioria corresponde a falsos independentes que são forçados a aceitar essa situação por falta de alternativas de emprego.

Concluindo, as reformas levadas a cabo durante a austeridade porque incidentes sobretudo sobre o enfraquecimento da segurança no emprego e da proteção no desemprego dos trabalhadores permanentes, sem contrapartidas suficientes em políticas de ativação e de incentivos à negociação salarial, promoveram a liberalização da regulação das relações de emprego, sem diminuição da segmentação do mercado de trabalho (Cardoso \& Branco, 2018; Cerdeira, Kovács \& Dias, 2015; Clauwaert \& Schömann, 2013; OIT, 2018).

Um tema não consensual é se para além de segmentado o mercado de trabalho regista uma mudança estrutural de polarização. Numa análise do período de 
Tabela 2 Trabalho temporário e trabalho temporário involuntário em Portugal e na UE28, 2007-2017

\begin{tabular}{|c|c|c|c|c|c|}
\hline & & \multicolumn{2}{|c|}{$\begin{array}{c}\text { Trabalho temporário } \\
\text { em percentagem do emprego }\end{array}$} & \multicolumn{2}{|c|}{$\begin{array}{l}\text { Trabalho temporário involuntário } \\
\text { em percentagem do trabalho temporário }\end{array}$} \\
\hline & & 2007 & 2017 & 2007 & 2017 \\
\hline $\begin{array}{c}\mathrm{H}-\mathrm{M} \\
\text { (15-64 anos) }\end{array}$ & $\begin{array}{l}\text { UE28 } \\
\text { PT }\end{array}$ & $\begin{array}{l}14,5 \\
22,3\end{array}$ & $\begin{array}{l}14,3 \\
22,0\end{array}$ & $\begin{array}{l}51,8 \\
81,7\end{array}$ & $\begin{array}{l}54.0 \\
82,4\end{array}$ \\
\hline $\begin{array}{l}\text { Homens } \\
\text { (15-64 anos) }\end{array}$ & $\begin{array}{l}\text { UE28 } \\
\text { PT }\end{array}$ & $\begin{array}{l}13,7 \\
21,6\end{array}$ & $\begin{array}{l}14,0 \\
22,3\end{array}$ & $\begin{array}{l}51,2 \\
81,4\end{array}$ & $\begin{array}{l}53,2 \\
81,7\end{array}$ \\
\hline $\begin{array}{l}\text { Mulheres } \\
\text { (15-64 anos) }\end{array}$ & $\begin{array}{l}\text { UE28 } \\
\text { PT }\end{array}$ & $\begin{array}{l}15,3 \\
23,0\end{array}$ & $\begin{array}{l}14,8 \\
21,7\end{array}$ & $\begin{array}{l}52,4 \\
82,0\end{array}$ & $\begin{array}{l}54,7 \\
83,0\end{array}$ \\
\hline $\begin{array}{c}\mathrm{H}-\mathrm{M} \\
\text { (25-64 anos) }\end{array}$ & $\begin{array}{l}\text { UE28 } \\
\text { PT }\end{array}$ & $\begin{array}{l}10,9 \\
18,7\end{array}$ & $\begin{array}{l}11,3 \\
18,7\end{array}$ & $\begin{array}{l}61,5 \\
84,7\end{array}$ & $\begin{array}{l}62,9 \\
86,1\end{array}$ \\
\hline $\begin{array}{c}\mathrm{H}-\mathrm{M} \\
(15-24 \text { anos) }\end{array}$ & $\begin{array}{l}\text { UE28 } \\
\text { PT }\end{array}$ & $\begin{array}{l}41,0 \\
53,1\end{array}$ & $\begin{array}{l}44,0 \\
65,9\end{array}$ & $\begin{array}{l}32,1 \\
72,5\end{array}$ & $\begin{array}{l}31,7 \\
68,3\end{array}$ \\
\hline
\end{tabular}

Fonte: Eurostat (LFS).

1986-2007, tendo por base os Quadros de Pessoal, Fonseca, Lima \& Pereira (2015), sugerem que Portugal tem vindo a registar uma trajetória de polarização do emprego derivada da evolução tecnológica de modo semelhante à dos Estados Unidos. Por seu lado, Centeno e Novo (2014) numa análise centrada nas desigualdades salariais em Portugal, num período de tempo próximo (1984-2009), também suportada nos Quadros de Pessoal, defendem ter havido uma mudança no padrão do crescimento do emprego. O padrão upgrading (melhoria da estrutura de qualificações) prevalecente no subperíodo 1984-1994 deu lugar ao padrão de crescimento polarizado no subperíodo de 1996-2009.

Estudos comparativos internacionais incidindo sobre os mesmos períodos, com suporte empírico diferente (Eurostat), sugerem evoluções muito diferenciadas. Por exemplo, Goos, Manning \& Salomons (2009), ao comparar a evolução do emprego em 16 países europeus de 1993-2006, refere que Portugal registou, nesse período, uma tendência de downgrading (maior crescimento relativo dos quintis inferiores), sendo uma exceção na tendência para a polarização da estrutura ocupacional que constatou nos restantes países analisados. Todavia, na análise relativa ao período de 1993-2010, a tendência para a polarização é verificada em Portugal tal como nos restantes 14 países europeus estudados (Irlanda, Bélgica, Espanha, Reino Unido, Grécia, Itália, Áustria, Dinamarca, Suécia, França, Noruega, Holanda e Alemanha). Fernández-Macías (2012), por sua vez, relativamente ao período 1995-2007, sublinha que Portugal apresenta uma tendência contrária à polarização, que é a middle-upgrading, ou seja, o maior crescimento relativo nos quintis intermédios. 
No que se refere aos anos mais recentes, não se conhecem estudos de autores nacionais. Todavia, a Eurofound (2017), nos estudos transnacionais que tem vindo a promover, sugere que Portugal teria registado uma tendência para a polarização no subperíodo de 2011-2013, seguida de uma tendência de melhoria da estrutura de emprego no período pós-crise 2013-2015.

\section{Aspetos metodológicos}

A análise da polarização do emprego exige fazer várias opções metodológicas relacionadas com as fontes de informação que deverão ser utilizadas, com o tipo de agrupamento das ocupações por níveis e com os critérios que suportam a classificação e a hierarquização dos empregos. Os resultados tenderão a ser condicionados por tais opções (Eurofound, 2015; Kovács \& Cerdeira, 2018).

O presente estudo segue a metodologia utilizada por Fernández-Macías (2012) e pelos vários estudos da responsabilidade da Eurofound (2013, 2014, 2015, 2016, 2017), adotando uma abordagem centrada nos empregos. Esta abordagem entende o emprego como a unidade de análise, que é definido como uma ocupação (ou posto de trabalho) num determinado sector, considerando que os dois conceitos - ocupação e sector - correspondem a duas dimensões fundamentais da divisão do trabalho. Dizendo respeito à divisão do trabalho dentro das organizações, a primeira, espelha a hierarquização aí existente dos papéis profissionais; a segunda, relativa ao sector, espelha a distribuição horizontal das atividades económicas entre as organizações produtoras de bens e serviços (Eurofound, 2015, p. 8).

Assim, usando a CPP (Classificação Portuguesa de Profissões, edição 2010, com desagregação a 2 dígitos) e a CPAE (Classificação Portuguesa das Atividades Económicas, revisão 3, 2008, desagregação a 2 dígitos), os empregos foram ordenados de acordo com o ganho médio mensal ${ }^{7}$ e organizados em quintis, a fim de permitir a comparação com os estudos da Eurofound. Cada quintil representa $20 \%$ dos trabalhadores por conta de outrem, a tempo completo. No quintil 1 situam-se os trabalhadores pior remunerados e no quintil 5 os trabalhadores com remunerações mais elevadas ${ }^{8}$. A informação estatística utilizada reporta-se a microdados a que foi possível aceder do anexo A (Quadro de Pessoal, contendo cerca de 3 milhões de observações) do Relatório Único, com obrigatoriedade de entrega anual por parte dos empregadores abrangidos pelo Código do Trabalho e pela legislação dele decorrente. Ficam excluídos dessa obrigação os serviços e órgãos que apenas tenham trabalhadores abrangidos pelo Regime de Contrato de Trabalho em Funções Públicas, pelo que o universo analisado não cobre naturalmente os últimos. A vantagem da utilização desta fonte estatística reside no facto de abranger todo o universo dos 
trabalhadores por conta de outrem do setor privado. Naturalmente que a sua limitação se prende com o facto de não abranger os trabalhadores da Função Pública, mas apenas aqueles que têm contrato individual de trabalho.

Os dados analisados dizem respeito aos trabalhadores por conta de outrem, a tempo completo. A subdivisão do período 2010-15 em dois: 2010-13 e 2013-15, deve-se ao facto do primeiro encerrar o período da maior contração do emprego e recessão económica; o segundo corresponde ao início de alguma estabilização e da retoma do emprego e do crescimento do PIB real, atendendo a que é a partir de meados de 2013 que se faz a inflexão da taxa do desemprego e do crescimento do PIB.

\section{Apresentação e discussão dos resultados}

A perda de cerca de 218 mil empregos líquidos, a tempo completo, que ocorreu entre 2010-2013, não se repartiu de uma forma equitativa pelos diferentes quintis de rendimento. Como evidencia a figura 1 , os mais penalizados foram os trabalhadores de nível intermédio da estrutura de qualificações e salários, com elevadas perdas de emprego que, nos casos do segundo e terceiro quintis, mais que duplicaram relativamente aos trabalhadores com remunerações mais baixas e mais altas. Assim, no que concerne à pior fase do desempenho da economia portuguesa (2010-2013), os nossos resultados vão ao encontro do estudo da Eurofound (2017), indicando, relativamente ao nosso país, uma tendência de polarização negativa, ou seja, polarização num contexto de redução geral de emprego. Tendo presente que Centeno e Novo (2014) e Fonseca, Lima e Pereira (2015) diagnosticaram uma tendência de polarização que remonta aos anos noventa, o caso português parece confirmar a literatura que sustenta que a crise aprofundou a tendência anterior para a polarização do emprego (Foote \& Ryan, 2012; Goos, Salomons \& Vandeweyer, 2013; Jaimovich \& Siu, 2013).

No que concerne ao segundo subperíodo de início da retoma económica (2013-2015), registou-se um acréscimo de cerca de 140 mil trabalhadores por conta de outrem, a tempo completo, tendo passado de cerca de 2 milhões e 212 mil para aproximadamente 2 milhões e 350 mil. Todos os quintis registam acréscimo de emprego, no entanto, o maior acréscimo ocorre no primeiro quintil, isto é, em ocupações com remunerações mais baixas. $\mathrm{O}$ crescimento deste quintil superou, em quase três pontos percentuais, o segundo e terceiro quintis, e quase 6 pontos percentuais o quintil das remunerações de topo, indicando um padrão de deterioração do emprego (downgrading) que é bem diferente do padrão de melhoria (upgrading) identificado pela Eurofound (2016, 2017).

A análise da evolução dos quintis ao longo de todo o período (2010-2015) revela que o primeiro é o único a registar uma ligeira evolução positiva, o que 

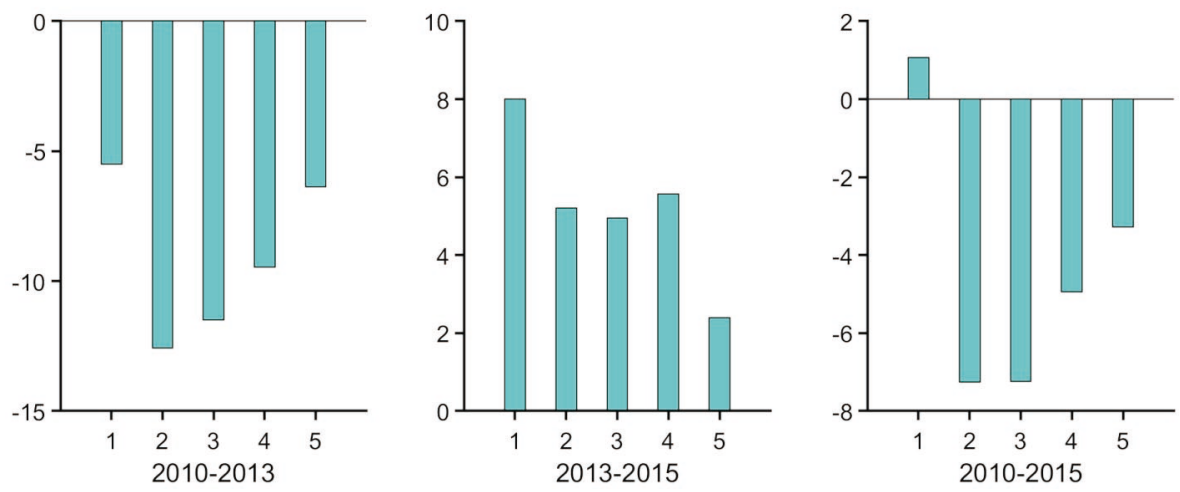

Figura 1 Evolução dos quintis: Total dos assalariados (2010-20015)

Fonte: Quadros de Pessoal, GEP/MTSS (cálculos dos autores).

significa que o número de assalariados atingiu e ultrapassou o detido em 2010. Os valores dos restantes quintis ficam aquém dos detidos nesse mesmo ano, registando o segundo e terceiro quintis quebras na ordem de 7 pontos percentuais e o quarto e quintis à volta de 5 e 3 pontos percentuais, respetivamente. Por conseguinte, a evolução dos quintis indica uma tendência para a polarização, ainda que com comportamento diferenciado nos subperíodos analisados.

No que concerne à evolução do emprego por quintis segundo o género, faz-se notar a divisão mais equilibrada do emprego em 2015 (feminino: 47\%; masculino: $53 \%$ ), com redução de 3 pontos percentuais da assimetria existente em 2010 (44\% contra 56\%). Esta redução relaciona-se com a forte concentração do emprego masculino nas atividades económicas mais afetadas pela crise (indústrias transformadoras e construção civil) e com a reconfiguração setorial do emprego que associou a retoma do emprego, expressa na aceleração da terceirização da economia ${ }^{9}$. Com efeito, dos 218 mil empregos líquidos perdidos de 2010-2013, 75\% foram empregos masculinos; na fase posterior da retoma do emprego (2013-2015), a criação do emprego foi mais uniformemente partilhada por ambos os sexos, ainda que, mesmo assim, o contributo do sexo feminino seja superior em 6 pontos percentuais (53\% dos 137 mil empregos líquidos criados).

Durante o período da contração do emprego (2010-13), os homens registam perda de emprego em todos os quintis, com particular relevância no primeiro (cerca de $17 \%$, que é aproximadamente o dobro da perda do quintil com ganhos mais elevados), o qual vem a crescer mais na fase da recuperação (figura 2). Já a mudança do perfil do emprego feminino é mais heterógena (figura 3), registando maiores descidas o primeiro e o terceiro quintis na fase de recuo do 

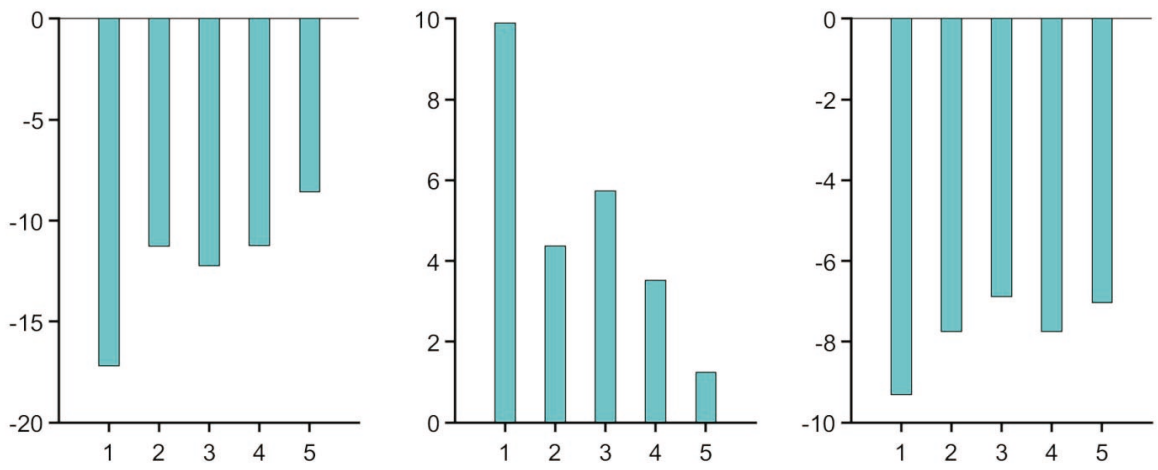

Figura 2 Evolução dos quintis: Homens (2010-2015)

Fonte: Quadros de Pessoal, GEP/MTSS (cálculos dos autores).
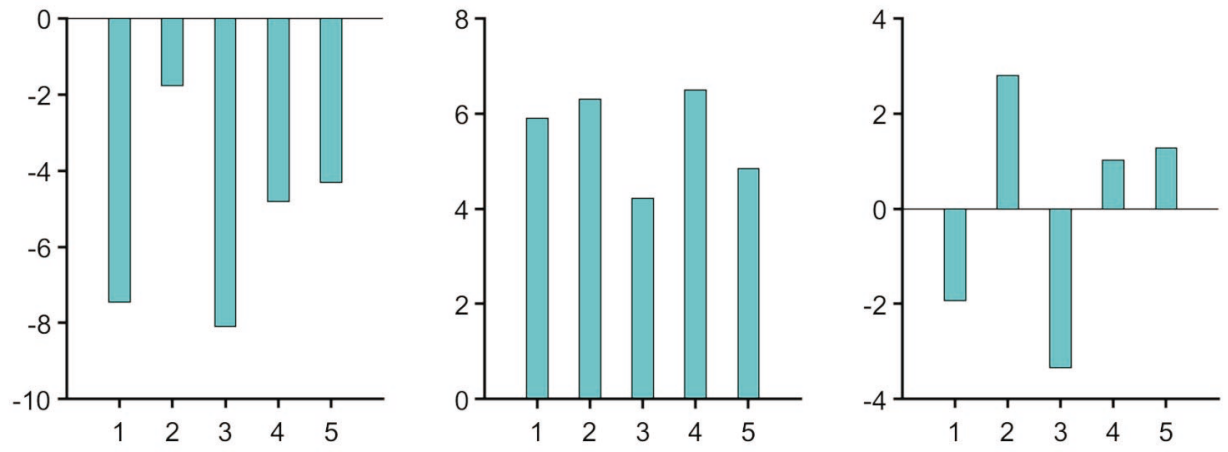

Figura 3 Evolução dos quintis: Mulheres (2010-2015)

Fonte: Quadros de Pessoal, GEP/MTSS (cálculos dos autores).

emprego e um crescimento relativamente uniforme de todos os quintis na fase da retoma (2013- 2015).

Em termos de evolução de todo o período (2010-2015), sublinha-se a melhor performance da evolução do emprego das mulheres, expressa na subida do segundo, quarto e quinto quintis e descida do primeiro (upgrading), bem diferente da evolução do emprego registada marcada pela descida de todos os quintis.

No que concerne ao perfil de mudança do emprego levando em conta os níveis de escolaridade, a análise dos figuras 4, 5 e 6 mostra que se registou uma tendência para a desqualificação (downgrading) geral nos períodos analisados, 
independentemente do nível de escolaridade dos trabalhadores, ainda que numa proporção um pouco diferente. O recuo do número de trabalhadores melhor remunerados (último quintil) na primeira fase (2010-13) é transversal a todos os níveis de escolaridade; na fase da retoma do emprego (2013-15), os assalariados com baixa escolaridade (figura 4) continuam a registar quebra no terceiro e quinto quintis. Os quintis dos assalariados com nível escolar superior ao básico (figuras 5 e 6 ) evoluem positivamente, com exceção do quinto quintil dos detentores do secundário que recua ligeiramente, mas com grande destaque para o crescimento do primeiro quintil.

A análise da evolução dos quintis faz então sobressair que, se a crise fez recuar os empregos com maiores ganhos, a retoma faz-se sobretudo no quintil com mais baixos salários, mesmo relativamente àqueles que detêm níveis de escolaridade elevados (figura 6). Assim, de 2010 a 2015, o primeiro quintil é o que regista quebra menos acentuada no caso da escolaridade básica e também o maior acréscimo nos restantes níveis de escolaridade. Observa-se, ainda, que, em geral, os trabalhadores com menor escolaridade foram os mais afetados pela crise e que impacto desta foi muito inferior, ou mesmo inexistente (exceto para o último quintil) para os trabalhadores com nível de escolaridade mais elevada. Esta evolução mostra que foram os trabalhadores com elevadas qualificações os que conseguiram mais empregos, mas com maior evidência para os quintis de mais baixas remunerações dentro desse grupo de escolaridade (figura 6).

Cerca de 195 mil dos 217 mil empregos perdidos de 2010 para 2013 dizem respeito a trabalhadores com idades inferiores aos 35 anos $(89,4 \%)$. No seguinte subperíodo (2013-2015), este grupo de trabalhadores regista apenas um incremento de aproximadamente 10 mil (7,5\%) dos cerca de 136 mil empregos líquidos criados, o que claramente espelha a clivagem existente na sociedade portuguesa entre os que ingressaram no mercado de trabalho há mais tempo e os que chegaram mais recentemente.

Como pode ser observado nas figuras 7 e 8, de 2010-2013, o grupo mais jovem (figura 7) regride em todos os quintis (entre aproximadamente $17 \%$ e $24 \%$ ), sendo o declínio um pouco menor no quintil com remunerações mais baixas; no subperíodo posterior, continua a redução do emprego em todos os quintis, com exceção do primeiro, único a registar incremento do emprego $(7 \%)$. No caso dos trabalhadores mais velhos (figura 8), há recuo do emprego nos primeiros quatro quintis e crescimento no quintil mais bem remunerado de 2010-2013, mas no segundo subperíodo (2013-2015), há acréscimo de postos de trabalho em todos os quintis, com maior ênfase nos quintis do meio (middle-upgrading).

Assim, de 2010 a 2015, a evolução dos quintis evidencia alguma deterioração (downgrading) do emprego até aos 35 anos e uma melhoria (upgrading) do emprego 

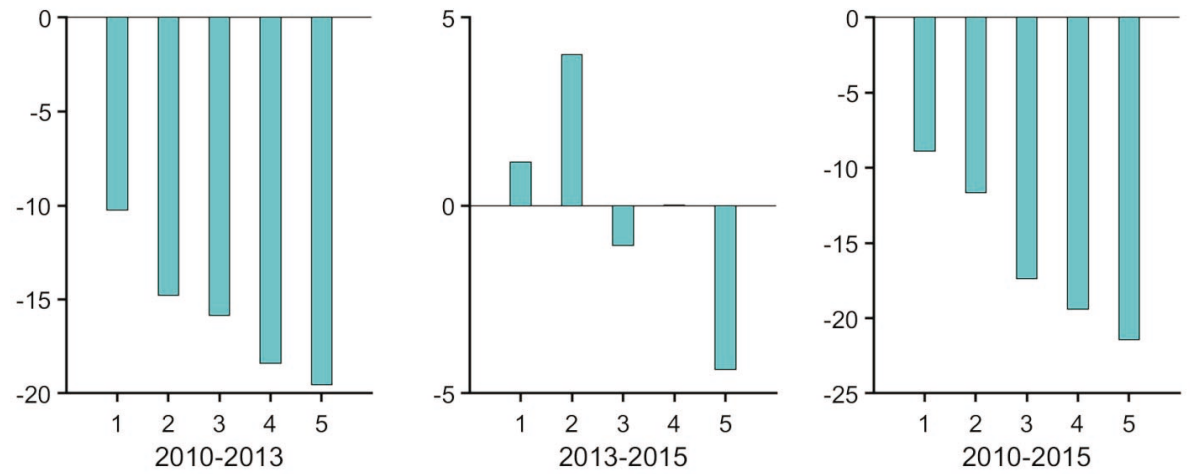

Figura 4 Evolução dos quintis: Assalariados com nível básico de escolaridade (2010-2015)

Fonte: Quadros de Pessoal, GEP/MTSS (cálculos dos autores).
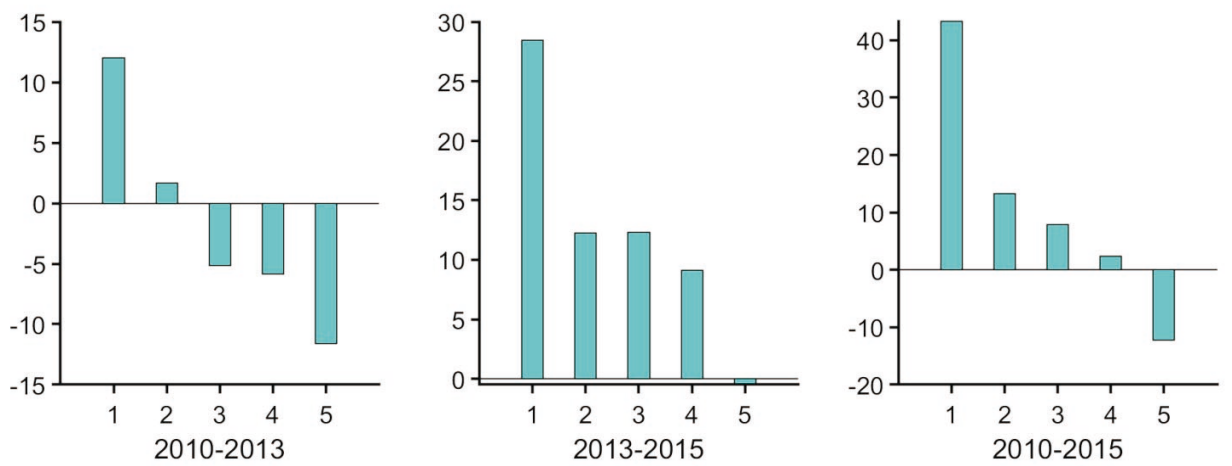

Figura 5 Evolução dos quintis: Assalariados com nível secundário de escolaridade (2010-2015)

Fonte: Quadros de Pessoal, GEP/MTSS (cálculos dos autores).

do segundo escalão etário, dando sustentação às teses das vantagens e desvantagens ligadas ao emprego permanente versus emprego precário.

Ainda que a maioria dos trabalhadores portugueses detenha um contrato permanente ${ }^{10}$, a percentagem de trabalhadores com contratos de trabalho atípicos sofreu um incremento de 5,7 pontos percentuais de 2010 para 2015. As figuras $9 \mathrm{e}$ 10 , onde se apresenta o perfil de mudança do emprego por quintil para os trabalhadores com contrato permanente e a prazo, sugerem que o declínio do emprego com maior segurança e com maiores possibilidades de evolução profissional e salarial se refletiu negativamente na evolução da estrutura do emprego. Assim, no que 

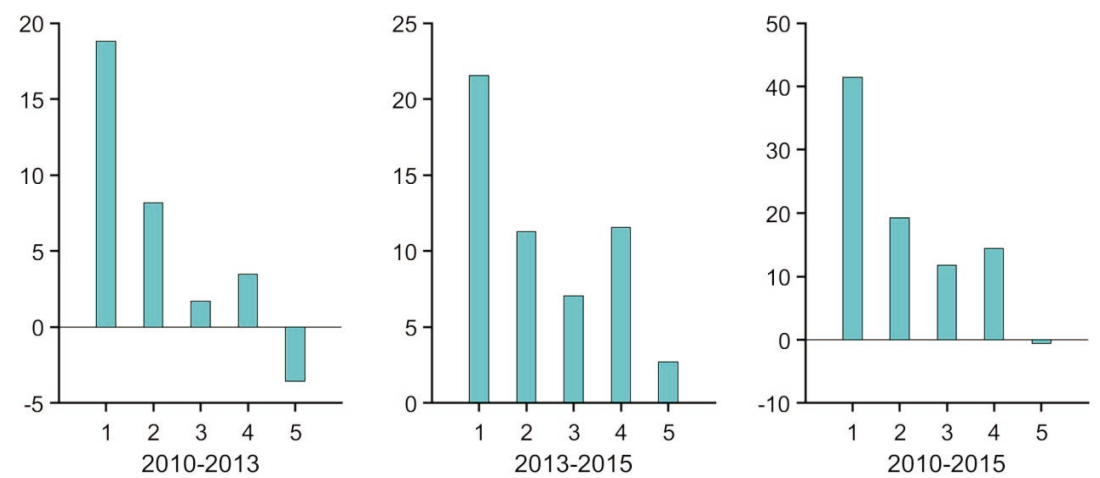

Figura 6 Evolução dos quintis: Assalariados com nível superior de escolaridade (2010-2015)

Fonte: Quadros de Pessoal, GEP/MTSS (cálculos dos autores).
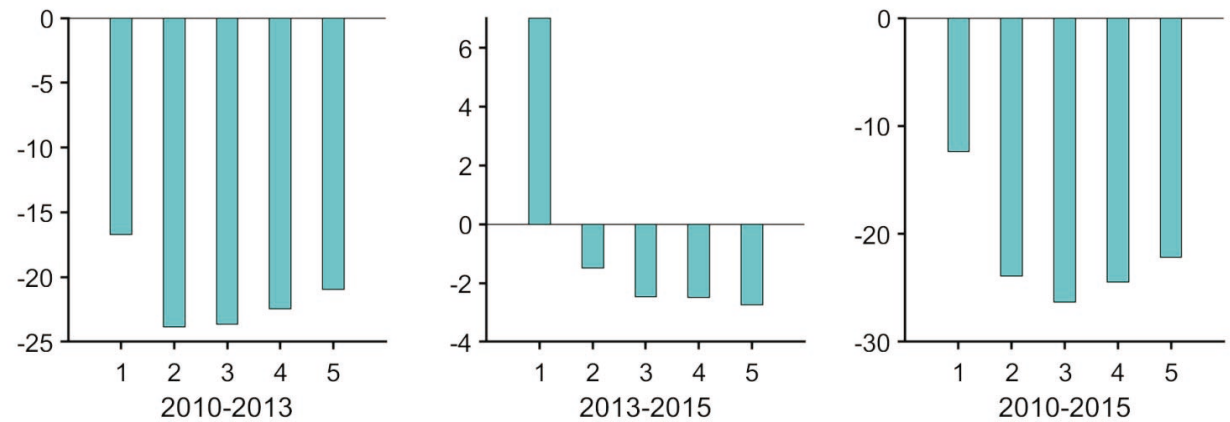

Figura 7 Evolução dos quintis: Assalariados com idade inferior a 35 anos (2010-2015)

Fonte: Quadros de Pessoal, GEP/MTSS (cálculos dos autores).

respeita aos contratos permanentes (figura 9), regista-se um declínio do emprego em todos os quintis, com peso ligeiramente superior nos quintis do meio (segundo e terceiro quintis) de 2010 a 2013. Na fase seguinte (2013-2015), quatro quintis registam incremento do emprego, mais significativo no primeiro, e recuo do emprego no segundo quintil. No período 2010-2015, os trabalhadores permanentes registam um perfil de mudança que se caracteriza pela polarização negativa, já que todos os quintis são afetados pelo declínio do emprego, com maior significado nos quintis médio (terceiro) e médio-baixo (segundo). No que concerne aos contratos a prazo (figura 10), há incremento das ocupações mais mal pagas e decréscimo das mais 

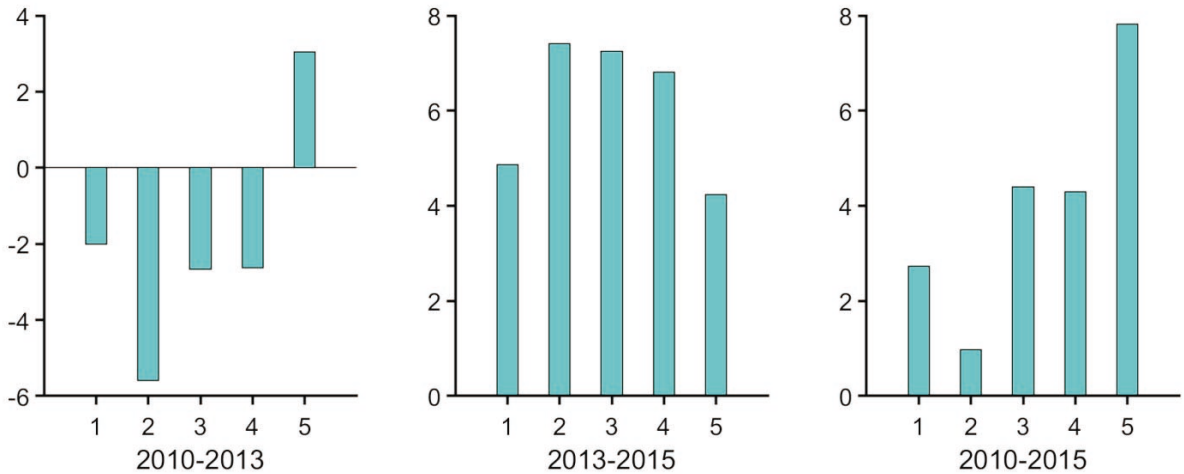

Figura 8 Evolução dos quintis: Assalariados com idade dos 35 aos 55 anos (2010-2015)

Fonte: Quadros de Pessoal, GEP/MTSS (cálculos dos autores).
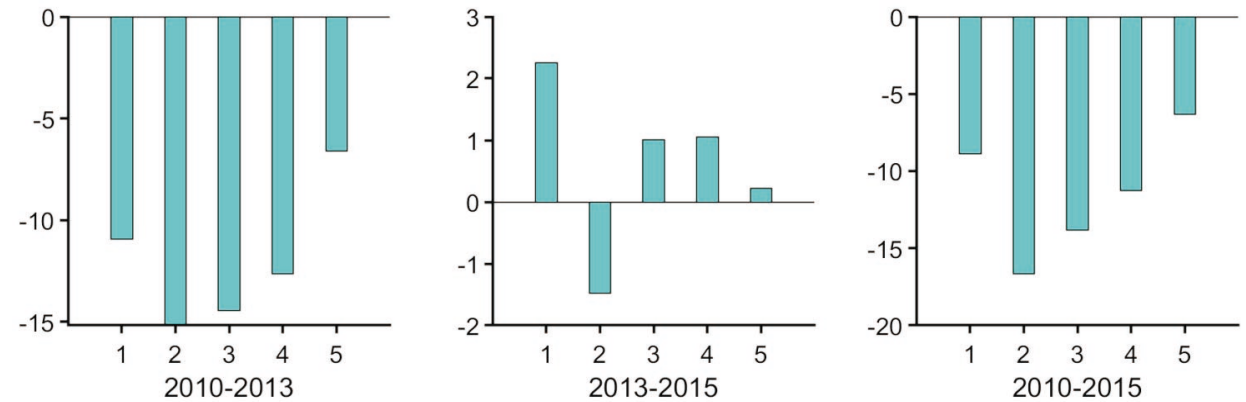

Figura 9 Evolução dos quintis: Contratados sem termo (2010-2015)

Fonte: Quadros de Pessoal, GEP/MTSS (cálculos dos autores).

bem remuneradas no período do pico da crise, mas há acréscimo do emprego em todos os quintis no período subsequente e também no conjunto de 2010-2015. De 2010 para 2015, regista-se um perfil de mudança de downgrading da segurança do emprego, quando comparamos a evolução observada nos contratos sem termo (permanentes) com a dos contratos com termo (não permanentes): redução do emprego em todos os quintis, no primeiro caso, contrastando com o aumento do emprego também em todos os quintis no segundo caso. 

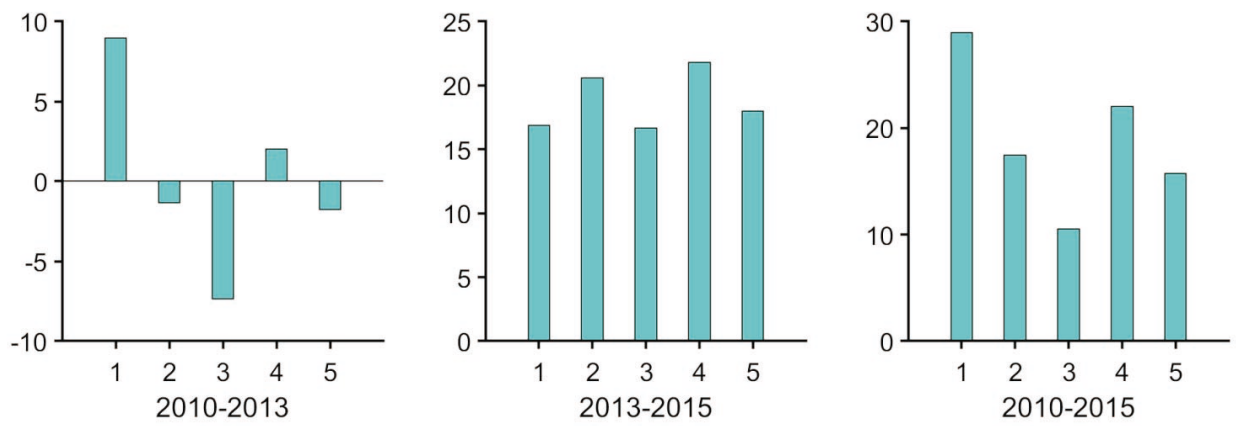

Figura 10 Evolução dos quintis: Contratados a termo certo (2010-2015)

Fonte: Quadros de Pessoal, GEP/MTSS (cálculos dos autores).

\section{Notas conclusivas}

A forte segmentação do mercado de trabalho baseada na coexistência de dois tipos de vínculos contratuais (permanentes e não permanentes), o alto grau de desigualdade, bem como a elevada proporção do emprego atípico são características de longa data do mercado de trabalho em Portugal. Essas características persistem, apesar da promoção da reforma laboral no âmbito do Programa de Ajustamento com o objetivo prioritário de reduzir a segmentação do mercado de trabalho.

O acréscimo do número de trabalhadores por conta de outrem na fase de retoma do emprego (2015) não foi suficiente para que este atinja os níveis do ano que precedeu o programa de apoio financeiro da Troika (2010). O decréscimo do emprego durante o período mais grave da crise (2010-2013), com grande incidência nos trabalhadores masculinos do setor secundário e a retoma do emprego no período 2013-2015 operaram uma recomposição do emprego, caracterizada pelo recuo do emprego masculino no setor secundário, em contrapartida do incremento do peso dos serviços e do emprego feminino. Estas mudanças surgem associadas à polarização negativa do emprego na primeira fase da crise, manifesta na maior redução relativa do emprego nos quintis médios, que é seguida, na fase da retoma do crescimento do emprego, por um padrão de desqualificação (downgrading), expresso no maior crescimento do emprego mal remunerado em comparação com os níveis médio e superior da hierarquia ocupacional. Assim, os nossos resultados confirmam a tendência para a polarização identificada pela Eurofound $(2016,2017)$ no que concerne ao pior período da crise (2010-2013), mas vão no sentido oposto no que se refere ao período da retoma do emprego (2013-2015). Como se referiu, enquanto os estudos da Eurofound, para esse período 
apontam para uma tendência de melhoria (upgrading) da estrutura do emprego, os nossos resultados apontam no sentido inverso (desqualificação). Todavia, a diferença das fontes estatísticas utilizadas pode ter influência na diferença dos resultados. Como foi referido relativamente aos aspetos metodológicos, os dados dos Quadros de Pessoal não incluem os trabalhadores da Função Pública e, por conseguinte, as conclusões devem ser entendidas tomando em consideração essa limitação.

Os nossos resultados também confirmam a literatura que sustenta que a crise aprofunda a tendência anterior para a polarização do emprego (Foote \& Ryan, 2012; Goos, Salomons \& Vandeweyer, 2013; Jaimovich \& Siu, 2013).

Os resultados obtidos sugerem que há diferenciação dos padrões de evolução do emprego segundo idade, género, escolaridade e tipo de contrato. A evolução do emprego afetou negativamente sobretudo os homens, os jovens com menos 35 anos, os menos escolarizados e os trabalhadores com contratos permanentes pela redução relativamente mais elevada do emprego em todos os quintis na fase da crise e no aumento mais elevado do emprego no primeiro quintil na fase da retoma. A evolução do emprego trouxe algumas melhorias para as mulheres e para o grupo etário de 35-55 anos, manifesta na relativamente menor redução do emprego nos diversos níveis na fase da crise e no maior aumento relativo de emprego inserido no padrão (upgrading) no caso das mulheres e crescimento relativo mais elevado de emprego nos quintis médios (middle upgrading) para o grupo etário de 35-55 anos. Apesar de os jovens com nível de escolaridade superior terem sido menos afetados pela crise no que se refere à redução do emprego, na fase da retoma o crescimento do emprego com baixo salário é relativamente maior inserindo-se no padrão de degradação (downgrading). É de notar que a evolução do emprego dos contratados a termo tende a mudar. Enquanto na fase da crise, o crescimento concentrou-se no primeiro quintil inserido num padrão de downgrading, na fase da retoma, verifica-se um aumento não muito diferenciado em todos os quintis.

Os dados apresentados sugerem que durante a crise e nos anos imediatos à crise, foi basicamente adotado uma estratégia de low road (via baixa), ou seja, melhorar a competitividade através de baixos custos salariais e mercado de trabalho liberalizado. Porém, a redução da segmentação e das desigualdades no mercado trabalho requer uma orientação de high road (via alta) nas políticas articuladas de emprego, de desenvolvimento/inovação e de educação/formação e na regulação de mercado de trabalho capazes de promover a mudança da estrutura do emprego no sentido do padrão de upgrading. 


\section{Notas}

Por decisão pessoal, os autores do texto escrevem segundo o novo acordo ortográfico.

1 Os contratos temporários incluem: 1) contrato de trabalho a termo resolutivo, definido como um contrato de trabalho genérico, com uma data de cessação determinada em termos precisos (na forma de dia, mês e ano em que fica definida a cessação do contrato de trabalho, caso o contrato não seja renovado); 2) o contrato de trabalho no âmbito de uma empresa de trabalho temporário, definido como a contratualização de trabalhadores através de um contrato nos termos do qual o empregador (ou seja, a empresa), no âmbito da estrutura da sua atividade ou prática profissional, coloca o trabalhador à disposição de um terceiro (ou seja, a empresa utilizadora) para executar um trabalho (ou seja, a afetação) sob a supervisão e direção dessa empresa utilizadora, em virtude de um contrato de prestação de serviços entre a empresa utilizadora e a empresa de trabalho temporário.

2 Sobre a liberalização dos contratos temporários e dos incentivos criados ao longo dos anos para a sua utilização ver: OIT (2018, capítulo 3).

3 A revisão deste Código teve como sustentação o Acordo Tripartido para um Novo Sistema de Regulação das Relações Laborais das Políticas de Emprego, subscrito para além do governo, por todas as confederações patronais e, do lado sindical, apenas pela UGT.

4 A reforma foi antecedida pelo designado Compromisso para o Crescimento, Competitividade e Emprego, apenas assinado do lado sindical pela UGT.

5 O despedimento individual por motivos económicos deixou de obedecer a uma ordem de antiguidade predefinida, ao mesmo tempo que passaram a ser possíveis os despedimentos por inadaptação ao posto de trabalho.

6 Uma análise detalhada das reformas do mercado de trabalho e da data da sua implementação pode ser encontrada em $\operatorname{OECD}$ (2017, pp. 127-155).

7 Os critérios mais comuns utilizados nos estudos para medir a qualidade dos empregos (job) e para os hierarquizar são os níveis escolares detidos pelas pessoas que ocupam os empregos e a mediana (ou média) do salário por hora de trabalho. Porém, a maior parte dos estudos adota o salário como critério, considerado que este é o atributo externo que melhor define a qualidade do trabalho (Wright e Dwyer (2003), ou considerando que os conceitos de salários, habilidades ou qualidade do trabalho, para fins práticos, são quase intercambiáveis, o que significa que o ranking de empregos por qualquer um deles conduz a resultados muito semelhantes (Eurofound, 2014; Fernández-Macías, 2012). No presente estudo também se optou pelo salário como critério de hierarquização dos empregos.

8 Para um maior desenvolvimento da metodologia ver, por exemplo, Eurofound (2016, pp. 7-9).

9 As indústrias transformadoras e a construção civil sofreram uma perda líquida de aproximadamente 127 mil trabalhadores, contra cerca de 94 mil nos serviços de 2010 
para 2013; de 2013-2015, enquanto o acréscimo líquido do número de trabalhadores por conta de outrem foi no setor dos serviços de cerca de 100 mil, no secundário foi apenas de 33 mil. Esta recomposição setorial do emprego é o principal fator explicativo da polarização registada na primeira fase (2010-13), na medida em que eram preponderantes os empregos de nível médio e médio baixo de qualificação/salário na construção civil e nas indústrias transformadoras.

10 A representação dos trabalhadores com contrato permanente, a tempo completo, evoluiu de 77,8\% em 2010 para 72,1\% em 2015.

\section{Agradecimentos}

Agradece-se ao GEP-MTSS o acesso aos dados dos Quadros de Pessoal, não lhes cabendo qualquer responsabilidade no tratamento por nós efetuado.

Agradece-se também o apoio financeiro concedido pela FCT (Fundação para a Ciência e a Tecnologia, Portugal) no âmbito do Projeto Estratégico UID / SOC / 04521/2013 (SOCIUS) e PEst-OE / EGE / UI0436 / 2014 (UECE).

\section{Referências}

Acemoglu, D. (2002). Technical change, inequality and the labour market. Journal of Economic Literature, 40(1), 7-72.

Acemoglu, D., \& Autor, D. H. (2011). Skills, tasks and technologies: Implications for employment and earnings. Em O. Ashenfelter, \& Card, D. (Eds.), Handbook of labor economics (Vol. 4B) (pp. 1043-1171). Holanda: North Holland.

Alves, N. A., Cantante, F., Baptista, I., \& Carmo, R. M. (2011). Jovens em transições precárias: Trabalho, quotidiano e futuro. Lisboa: Mundos Sociais.

Atkinson, J. (1985). Flexibility, uncertainty and manpower management (IMS Report No. 89). Brighton: Institute of Manpower Studies.

Autor, D. H. (2010). The polarization of job opportunities on the US labour market: Implications for employment and earnings. Washington, DC: Hamilton Project and the Center for American Progress.

Autor, D. H. (2013). The 'task approach' to labor markets: An overview (NBER Working Paper No. 18711). Cambridge, MA: National Bureau of Economic Research.

Autor, D. H. (2015). Why are there still so many jobs? The history and future of workplace automation. Journal of Economic Perspectives, 29(3), 3-30.

Autor, D. H., \& Dorn, D. (2013). The growth of low-skilled service jobs and the polarization of the US labour market. American Economic Review, 103(5), 1553-1597.

Autor, D. H., Dorn, D., \& Hanson, G. H. (2016). The China shock: Learning from labor market adjustment to large changes in trade. Annual Review of Economics, 8, 205-240. 
Autor, D. H., Katz, L. F., \& Kearney, M. S. (2006). The polarization of the US labor market. American Economic Review: Papers and Proceedings, 96(2), 189-194.

Autor, D. H., Katz, L. F. \& Krueger, A. B. (1998). Computing inequality: Have computers changed the labor market?. Quarterly Journal of Economics, 113(4), 1169-1213.

Autor, D., H., Levy, F. \& Murnane, R. J. (2003). The skill content of recent technological change: An empirical exploration. Quarterly Journal of Economics, 118(4), 1279-1333.

Barbieri, P. (2009). Flexible employment and inequality in Europe. European Sociological Review, 25(6), 621-628.

Berger, S., \& Piore, M. (1980). Dualism and discontinuity. Cambridge: Cambridge University Press.

Brewster, C., Mayne, L., Tregaskis, O. M. (1997). Flexible working in Europe. Journal of World Business, Summer, 32, 133-152.

Cardoso, D., \& Branco, D. (2018). Liberalised dualisation. Labour market reforms and the crisis in Portugal: A new departure. European Journal of Social Security, 20(1), 31-48.

Casaca, S. F. (2005). Flexibilidade, emprego e relações de género: a situação de Portugal no contexto da União Europeia. Em I. Kovács (Org.), Flexibilidade de emprego: riscos e oportunidades (pp. 55-89). Oeiras: Celta.

Casaca, S. F. (2012). Mercado de trabalho, flexibilidade e relações de género: Tendências recentes. Em S. F. Casaca (Org.), Mudanças laborais e relações de género - Novos vetores de (des)igualdade (pp. 9-50). Lisboa: Fundação Económicas / Almedina.

Castells, M. (1998). La era de la información: Economía, sociedad y cultura (Vol. 1). Madrid: Alianza.

Centeno, M., \& Novo, Á. A. (2012). Segmentação. Boletim Económico. Banco de Portugal, 18(1), 7-30.

Centeno, M., \& Novo, Á. A. (2014). When supply meets demand: Wage inequality in Portugal. European Labor Studies, 214, 3-23.

Cerdeira, M. C. (2004). Dinâmicas de transformação das relações laborais portuguesas. Lisboa: DGRET-MTSS.

Cerdeira, M. C., Casaca, S. F., Santos, M. J., Sampaio, J. J., \& Silva. J. L. (1999). Novas modalidades de emprego. Lisboa: Ministério do Trabalho e da Solidariedade.

Cerdeira, M. C., Kovács, I., \& Dias, J. (2015). Dinâmicas de erosão das relações laborais portuguesas no contexto da crise. Proceedings of First International Meeting of Industrial Sociology, Sociology of Organizations and Work (pp. 634-653). Lisboa: APSIOT.

Clauwaert, S., \& Schömann, I. (2013). The crisis and national labour law reforms: A mapping exercise. Country report: Portugal last update: January 2013 (Working Paper, N. ${ }^{\circ}$ 2012.04). ETUI.

CLBRL (Comissão do Livro Branco das Relações Laborais). (2007). Livro branco das relações laborais. Lisboa: MTSS.

Doeringer, P. B., \& Piore, M. J. (1971). Internal labor markets and manpower analysis. Heath Lexington.

Dornelas, A., Ministro, A., Lopes, F. R., Cerdeira, M. C., Galego, P., \& Sousa, S. C. (2006). Livro verde sobre as relações laborais. Lisboa: MTSS. 
Dornelas, A., Ministro, A., Lopes, F. R., Albuquerque, J. L., Paixão, M. M., \& Santos, N. C. (2011). Emprego, contratação coletiva de trabalho e proteção da mobilidade profissional em Portugal. Lisboa: MTSS.

Edwards, R. C. (1979). Contested terrain: The transformation of the workplace in the twenthieth century. Nova Iorque: Basic Books.

Eurofound. (2013). Employment polarisation and job quality in the crisis: European jobs monitor 2013. Dublin: Eurofound.

Eurofound. (2014). Drivers of recent job polarisation and upgrading in Europe: European jobs monitor 2014. Dublin: Eurofound.

Eurofound. (2015). Upgrading or polarisation? Long-term and global shifts in the employment structure: European jobs monitor 2015. Luxemburgo: Publications Office of the European Union.

Eurofound. (2016). What do Europeans do at work? A task-based analysis: European jobs monitor 2016. Luxemburgo: Publications Office of the European Union.

Eurofound. (2017). Occupational change and wage inequality: European jobs monitor 2017. Luxemburgo: Publications Office of the European Union.

Fernández-Macías, E. (2012). Job polarization in Europe? Changes in the employment structure and job quality, 1995-2007. Work and Occupations, 39(2), 157-182.

Fonseca, T., Lima, F., \& S. Pereira (2015). Job polarization, technological change and routinization: Evidence from Portugal. Preliminary version. Disponível em http://www.apdr.pt/pej2015/papers/19.pdf

Foote, C., \& Ryan, R. W. (2012). Labor-market polarization over the business cycle (NBER Working Paper, N. ${ }^{\circ}$ 21030). Cambridge, MA: National Bureau of Economic Research.

Gallie, D. D., White, M., Cheng, Y., \& Tomlinson, M. (1998). Restructuring the employment relationship. Oxford: Clarendon Press.

Goldin, C., \& Katz, L. F. (1996). Technology, skill and the wage structure: Insights from the past. AEA Papers and Proceedings, 86(2), 252-257.

Golsch, K. (2003). Employment flexibility in Spain and its impaction transitions to adulthood. Work, Employment and Society, 17(4), 691-718.

Goos, M., \& Manning, A. (2007). Lousy and lovely jobs: The rising polarization of work in Britain. The Review of Economics and Statistics, 89(1), 118-133.

Goos, M., Manning, A., \& Salomons, A. (2009). Job polarization in Europe. The American Economic Review, 99(2), 58-63.

Goos, M., Manning, A., \& Salomons, A. (2011). Explaining job polarization: The roles of technology, offshoring and institutions (Discussion Paper Series 11.34). Leuven: University of Leuven, Center of Economic Studies.

Goos, M., Salomons, A., \& Vandeweyer, M. (2013). Job polarization during the Great Recession and beyond (Euroforum policy paper KU Leuven, N. ${ }^{\circ}$ 2). Leuven: Metaforum KU Leuven.

Harrison, B. (1994). Lean and mean. Nova Iorque/ Londres: The Guilford Press.

ILO. (2013). Global employment trends for youth 2013: A generation at risk. Genebra: ILO. 
ILO. (2016). World employment social outlook - Trends for youth 2016. Genebra: ILO.

Jaimovich, N., \& Siu, H. (2012). The trend is the cycle: Job polarization and jobless recoveries (NBER Working Paper, N. $\left.{ }^{\circ} 18334\right)$. NBER.

Kalleberg, A. L. (2000). Nonstandard employment relations: Part-time, temporary and contract work. Annual Review of Sociology, 26(1), 341-65.

Kalleberg, A. L. (2011). Good jobs, bad jobs: The rise of polarized and precarious employment systems in the United States, 1970s to 2000s. Nova Iorque: Russel Sage Foundation.

Kovács, I. (2005). Emprego Flexível em Portugal: Alguns Resultados de um Projecto de Investigação. Em I. Kovács (Org.), Flexibilidade de emprego: Riscos e oportunidades (pp. 11-51). Oeiras: Celta Editora.

Kovács, I. (2014). Trayectorias laborales y de vida de jóvenes: Un análisis cualitativo. Sociología del Trabajo, 80, 28-50.

Kovács, I., \& Casaca, S. F. (2007). Flexibilidad y desigualdad en el trabajo: Tendências y alternativas europeas. Sociología del Trabajo, 61, 99-124.

Kovács, I., \& Cerdeira, M, C. (2018). Controvérsias sobre a polarização e as desigualdades salariais. Em Atas do XVII ENSIOT (pp. 110-122). Lisboa: APSIOT.

Kovács, I., \& Chagas Lopes, M. (2012). A juventude e o emprego: entre a flexibilidade e a precariedade. Em S. F. Casaca (Org.), Mudanças laborais e relações de género: Novos vetores de (des)igualdade (pp. 51-86). Lisboa: Fundação Económicas \& Almedina.

Kovács, I., Moniz, A. B., Cerdeira, M. C., \& Bairrada M. (1994). Qualificações e mercado de trabalho. Lisboa: IEFP.

Lindbeck, A., \& Snower, D. J. (2001). The insider-outsider theory. Journal Economic Perspectives, 15(1), 165-188.

López Calle, P., \& Castillo, J. J. (2004). Los hijos de las reformas laborales. Madrid: UGT.

Marques, A. P. (2010). 'Sacralização' do mercado de trabalho. Jovens diplomados sob o signo da precariedade. Configurações, 7, 65-89.

Maruani, M. (2003). Travail et emploi des femmes. Paris: La Découverte.

Mishel L., Schmitt J., \& Shierholz, H. (2013). Assessing the job polarization explanation of growing wage inequality (EPI Working Paper, N. $\left.{ }^{\circ} 285\right)$. Washington, DC: Economic Policy Institute.

OECD. (2010). OECD employment outlook 2010. Paris: OECD Publishing.

OECD. (2014). OECD employment outlook 2014. Paris: OECD Publishing.

OECD. (2016). OECD employment outlook 2016. Paris: OECD Publishing.

OECD. (2017). Labour market reforms in Portugal 2011-2015 - A preliminary assessment. Paris: OECD Publishing.

OECD. (2018). OECD employment outlook 2017. Paris: OECD Publishing.

Oesch, D. (2013). Occupational change in Europe: How technology and education transform the job structure. Oxford: Oxford University Press.

Oesch, D., \& Menès, J. R. (2011). Upgrading or polarization? Occupational change in Britain, Germany, Spain and Switzerland, 1990-2008. Socio-Economic Review, 9(3), 503-531.

OIT. (2018). Trabalho digno em Portugal 2008-18: Da crise à recuperação Bureau Internacional do Trabalho. Genebra: BIT. 
Paugam, S. (2000). La salarié de la precarité. Les nouvelles formes de l' integration profissionnel. Paris: PUF.

Piore, M. (1972). Note for a theory of labor market stratification (Working Paper Departament of Economics, N. ${ }^{\circ}$ 95). Cambridge, MA: MIT.

Piore, M. (1978). Dualism in the labor market: A response to uncertainty flux. The case of France. Revue Économique, 29(1), 26-48.

Rosenberg, S. (1989). From segmentation to flexibility: A selective survey. Labour and Society, 14(4), 363-407.

Rosenberg, S. (2007). From segmentation to flexibility to segmentation amidst flexibility: The case of the United States. Économies et sociétés, Série: Socio-Économie du travail, (28), 897-924.

Rosenberg, S., \& Lapidus, J. (1999). Contingent and non-standard work in the United States. Em A. Felstead, \& N. Jewson (Eds.), Global trends in flexible work (pp. 62-83). Londres: Macmillan Press.

Rubery, J. (2007). Developing segmentation theory: A thirty-year perspective. Économies et Sociétés, 28(6), 941-64.

Rubery J., \& Piasna, A. (2017). Labour market segmentation and deregulation of employment protection in EU. Em A. Piasna, \& M. Myant (Eds.), Myths of employment deregulation: How it neither creates jobs nor reduces labour market segmentation (pp. 43-60). Bruxelas: ETUI.

Rueda, D. (2014). Dualization, crisis and the welfare state. Socio-Economic Review, 12(2), 381-407.

Tüzemen, D., \& Willis J. (2013). The vanishing middle: Job polarization and workers' response to the decline in middle-skill jobs. Economic Review, (qi), 5-32.

Valadas, C. (2017). A changing labour market under the intensification of dualization. The experience of a southern European society. Social Policy $\mathcal{E}$ Administration, 52(2), 223-403.

Wright, E. O., \& Dwyer, R. E. (2003). The patterns of job expansions in the United States: A comparison of the 1960s and 1990s. Socio-Economic Review, 1, 289-325.

Yoon, Y., \& Chung, H. (2015). New forms of dualization? Labour market segmentation patterns in the UK from the late 90s until the post-crisis in the late 2000s. Social Indicators Research, 128(2), 609-631.

Data de submissão: 15/05/2019 | Data de aceitação: 06/09/2019 